\title{
Effect of the Sonas Programme on Communication in People with Dementia: A Randomized Controlled Trial
}

\author{
Benedicte Sørensen Strøm ${ }^{a} \quad$ Knut Engedal $^{b, c} \quad$ Jurate Saltyte Benth ${ }^{d}$ \\ Ellen-Karine Grov ${ }^{\mathrm{e}}$ \\ ${ }^{a}$ Center for Diakonia and Professional Practice, VID Specialized University, Oslo, Norway; \\ ${ }^{b}$ Norwegian Advisory Unit for Aging and Health, Vestfold Hospital HF, Tønsberg, Norway; \\ ${ }^{c}$ Department of Geriatrics, Oslo University Hospital, Oslo, Norway; ${ }^{d} \mathrm{H} \varnothing \mathrm{GH}$, Research \\ Centre, Akershus University Hospital, Lørenskog, Norway; ${ }^{e}$ Oslo and Akershus University \\ College of Applied Sciences, Oslo, Norway
}

\author{
Keywords \\ Communication · Dementia - Elderly · The Sonas programme
}

\begin{abstract}
Background: Strategies to improve communication in people with dementia are warranted. We examined the effect of the Sonas programme on communication ability in persons with moderate to severe dementia. Methods: A 24-week 3-armed (Sonas, reading, and control group) randomized controlled trial including 120 nursing home residents with dementia was conducted; 105 completed the follow-up assessments. The main outcome was change in communication abilities measured by the Holden Communication Scale (HCS). Results: We found no overall significant effect of the Sonas programme with regard to communication ability as measured by the HCS. However, an effect between the Sonas group and the reading group and between the Sonas group and the control group from T0 to T1 and T2 was found, as well as a significant improvement in communication in the Sonas group. Among people with severe dementia, the Sonas group scored significantly better on the HCS compared to the reading group after 12 weeks, but not after 24 weeks. Conclusion: This study failed to document an overall effect of the Sonas programme on communication; however, the findings indicate that the Sonas programme has a significant effect on communication among those with severe dementia.




\section{Introduction}

Approximately 47 million people worldwide are estimated to live with dementia and the incidence per year is estimated to be 9.9 million cases [1].

Dementia presents a wide range of symptoms, such as cognitive impairment and behavioural and motoric changes. Communication difficulties are among the earliest symptoms of dementia [2], especially verbal communication difficulties, which are seen as a significant problem among those with severe dementia [3,4]. However, the urge to communicate and the need to be part of the society will remain, regardless of the degree of dementia [5]. The lack of verbal communication can make people with dementia appear unreachable and lead to fewer attempts by carers to communicate with the person [6], and even result in "social death" [7].

People with dementia at a severe stage are less able to be active and therefore tend to be isolated and bored. The use of psychosocial interventions in dementia care is highly recommended since antipsychotic treatment may have serious side effects in the management of behavioural and psychological symptoms of dementia [8, 9]. Psychosocial interventions are also referred to as a way of promoting person-centred care for individuals with dementia [10].

Lubinski [11] emphasizes the importance of cognitive stimulation through the senses for those with dementia. This is supported by Vozzella [12] who claims that as the person regresses, the need for stimulation increases. Bakshi [13] found that individuals with moderate to severe dementia were given less antipsychotic medication after having received stimulation. However, despite the evidence that communication difficulties are problematic for persons with dementia, a review conducted by Strøm et al. [14] of available sensory stimulation strategies identified only one quantitative study that measured the effect on communication. This study, conducted by Hutson et al. [15], found no effect of the Sonas programme on communication.

The majority of available sensory stimulation interventions include stimulation of only 1 of the senses, such as music, light therapy, acupressure/reflexology, massage/aromatherapy and doll therapy/pet therapy/toy therapy [14]. However, the Sonas programme, which is a multi-sensory stimulation programme developed by Sr. Mary Threadgold in 1990, involves cognitive, sensory, and social stimulation, including all 5 senses: touch, smell, taste, hearing, and sight. The programme is a therapeutic activity for people who have significant communication impairment, primarily as a result of dementia. The aims of the Sonas programme are: (1) to activate whatever potential for communication has been retained by an older person with communication impairment, (2) to encourage the creation of an environment which will facilitate communication, and (3) to have activation of the potential for communication recognized and accepted as an essential part of care planning for older people. However, research investigating the effectiveness of the Sonas programme is limited with only few studies published, one of which assessing the effect on communication as a secondary outcome measure.

Of the relevant studies on this topic, the first was an observation study carried out by Brown [16] who reported some positive changes in well-being, self-confidence, self-esteem, and trust as well as improved alertness, happiness, quality of life (QoL), and relaxation after attending the Sonas sessions. No benefit was found on agitation and aggression. However, this study has several limitations, with an unknown number of participants and undisclosed length of the intervention period as well as outcome measures, and no control group. Parrish et al. [17] used Dementia Care Mapping to observe 51 participants with dementia in day hospitals and care wards in institutions attending Sonas sessions. Although no benefit was reported on reduced agitation or aggression, a significant number of participants showed a 
positive change in well-being after attending the Sonas sessions as well as being more animated and initiating conversation and singing.

The first randomized controlled trial (RCT) measuring the effect of the Sonas programme was conducted in 2003 by Jackson et al. [18]. All 75 participants were randomly selected to either attend a weekly Sonas session for 8 weeks or be part of the control group where the participants received standard care. No significant differences were found between the groups in relation to aggression, agitation, depression or cognitive impairment. A recent pilot RCT [15] included 36 residents with moderate to severe dementia, of whom 20 participated in Sonas sessions twice weekly over a period of 7 weeks; no statistically significant differences in depression, anxiety, communication, and QoL were reported. However, there was some improvement for both groups in relation to depression and anxiety, where the control group demonstrated greater improvement than the Sonas group. Further, the Sonas group demonstrated an improvement in communication ability and QoL, as well as a greater reduction in behavioural and mood disturbance than the control group.

The need for high-quality research investigating psychosocial interventions for older people with dementia has been emphasized [19]. In addition, only few studies have investigated the effectiveness of techniques to improve communication for people with dementia, which is of importance as communication is essential for social life of people regardless of cognitive function [20]. With just few published studies examining the effect of the Sonas programme, some showing methodological limitations, short duration and small sample sizes, the overall aim of this study was to examine the effect of the Sonas programme on communication ability for people with moderate to severe dementia living in a nursing home. The secondary aim was to explore if any effect could be related to cognitive function and different aspects of communication.

\section{Method}

The study is reported according to the CONSORT statement 2010 [21] and the extended version of the CONSORT statement for non-pharmacological treatment [22].

\section{Study Design}

The study is an RCT where the participants were assigned to 1 of the 3 groups for 24 weeks: (1) the Sonas programme, (2) the reading group, and (3) standard care. The reading group was set up in order to rule out the possibility that an effect of attending the Sonas sessions could be caused by the attention given by staff leading the group, rather than the actual Sonas programme. The study took place from April to October 2014. Data collection was carried out at baseline (T0) before randomization, and after 12 weeks (T1) and 24 weeks (T2), respectively.

\section{Setting}

In all 168 nursing homes in Dublin, Ireland, and the 5 surrounding counties, all registered with the independent authority, i.e., "Health Information and Quality Authority" (HIQA), were considered eligible. The goal of HIQA is to perform continuous improvement in Ireland's health and social care services [23]. Only long-term facilities with at least 40 beds and which had not used the Sonas programme earlier were initially chosen to take part in the study. Of the 168 nursing homes, 47 have less than 40 beds, 18 are hospitals, and 78 had already used the Sonas programme according to the last inspection report carried out by HIQA. The remaining 25 nursing homes received an e-mail about the trial. The first author surveyed the 25 nursing homes to determine whether there were adequate numbers of potential partici- 
Fig. 1. The Sonas programme.

$$
\begin{aligned}
& \text { The programme consists of the following elements: } \\
& \text { - Signature tune and greeting song } \\
& \text { - Exercises to music } \\
& \text { - Smell } \\
& \text { - A "sing-along" which includes three familiar songs } \\
& \text { - Relaxation music/massage (the senses of taste and touch are stimulated) } \\
& \text { - Music with percussion instruments } \\
& \text { - Joining in proverbs } \\
& \text { - Listening to poetry } \\
& \text { - Contribution } \\
& \text { - Second "sing-along" } \\
& \text { - Closing song and signature tune }
\end{aligned}
$$

pants with dementia. Eight nursing homes agreed to participate; however, 1 withdrew. Two more counties were included and 1 of the 9 eligible nursing homes in these counties accepted to participate. Another nursing home withdrew and 1 did not have enough participants for 2 groups, which left us with 6 nursing homes for this RCT (Fig. 1).

\section{Participants}

The participants were recruited between January and March 2014 and the Director of Nursing in each nursing home identified potential male and female residents. A total of 147 persons were considered eligible for the study. Informed consent was obtained from the nextof-kin since the persons with dementia were unable to sign the informed consent. Persons were considered suitable for participation when they were $>65$ years of age, were diagnosed with dementia, had moderate to severe cognitive functioning as classified by pre-trial MiniMental State Examination (MMSE) scores of 0-20, spoke English and were living in the nursing home. Persons at a palliative stage, those with major depression, current or partial remission, severe pain, or those having been exposed to previous Sonas sessions were not included. Three of the nursing homes had enough eligible participants for 3 groups of 8 , while the other 3 only had enough eligible participants for 2 groups. This left us with 120 participants, while 27 were left out of the study.

\section{Randomization Process}

Due to ethical considerations, it was decided beforehand that each nursing home would have 1 Sonas group in order to give them the possibility to attend a new programme. The Director of Nursing at each site and this article's first author placed the name of the participants in a container and study participants were then drawn: 24 participants from 3 nursing homes and 16 from the other 3 nursing homes. After baseline data had been collected, the randomization was carried out by the same persons.

The participants were randomly assigned to either the Sonas group $(n=48)$, the reading group ( $n=32)$ or the control group $(n=40)$, by drawing lots. For the nursing homes with 24 eligible participants, the participants were randomly allocated to 1 of the 3 groups. For the nursing homes with 16 eligible participants, 8 were first randomly allocated to the Sonas group, whereas the remaining 8 participants were randomly allocated to either a reading or control group, by drawing lots.

\section{Intervention}

The Sonas programme was carried out twice a week in groups of 8 residents over a period of 24 weeks. Each session lasted $45 \mathrm{~min}$ and was led by a person trained in the Sonas programme (Sonas licensed practitioner) and an assistant. The programme consists of 13 
Table 1. Characteristics of participants at baseline

\begin{tabular}{lcccc}
\hline Characteristics & $\begin{array}{l}\text { Total } \\
(n=120)\end{array}$ & $\begin{array}{l}\text { Sonas group } \\
(n=48)\end{array}$ & $\begin{array}{l}\text { Reading group } \\
(n=32)\end{array}$ & $\begin{array}{l}\text { Control group } \\
(n=40)\end{array}$ \\
\hline Gender & & & & \\
$\quad$ Women & $93(77.5)$ & $40(83.3)$ & $25(78.1)$ & $28(70)$ \\
$\quad$ Men & $27(22.5)$ & $8(16.7)$ & $7(21.9)$ & $12(30)$ \\
Marital status & $36(30)$ & $12(25.0)$ & $11(34.4)$ & $13(32.5)$ \\
$\quad$ Single & $22(18.3)$ & $8(16.7)$ & $6(18.8)$ & $8(20.0)$ \\
$\quad$ Married & $61(50.8)$ & $27(56.3)$ & $15(46.9)$ & $19(47.5)$ \\
$\quad$ Widowed & $1(0.8)$ & $1(2.1)$ & $0(0)$ & $0(0)$ \\
$\quad$ Divorced & $63(52.5)$ & $29(60.4)$ & $15(46.9)$ & $19(47.5)$ \\
Degree of cognitive function & $57(47.5)$ & $19(39.6)$ & $17(53.1)$ & $21(52.5)$ \\
$\quad$ Severe (MMSE score 0-10) & $84.8 \pm 7.0$ & $86.1 \pm 6.6$ & $84.9 \pm 7.2$ & $83.3 \pm 7.1$ \\
$\quad$ Moderate (MMSE score 11-20) & $9.0 \pm 7.1$ & $7.7 \pm 6.7$ & $10.0 \pm 7.2$ & $9.7 \pm 7.5$ \\
Age, years & $22.0 \pm 11.9$ & $24.7 \pm 12.1$ & $18.2 \pm 12.0$ & $21.9 \pm 10.9$ \\
MMSE score & & & \\
HCS score & & & & \\
\hline
\end{tabular}

Values are mean \pm standard deviation or $n(\%)$. MMSE, Mini-Mental State Examination; HCS, Holden Communication Scale.

elements and follows the same structure each time, believing that repetition is a way of helping the individual to remember [24]. The participants are seated in a semi-circle and the session begins with a welcome song where each one is individually greeted by name (Fig. 1). The reading group received 45 min of reading from a newspaper twice a week for 24 weeks. The participants of the control group did not participate either in the Sonas sessions or the reading groups, but continued with their daily routines, for example, attending the activity programme set up by the nursing home. The staff (Sonas licensed practitioners and care assistants) involved in the study, either received (1) a 3 days' training consisting of training and support in the Sonas programme or (2) preparation to lead the reading group by this article's first author. The other staff did not receive any extra training.

\section{Main Outcome and Assessments}

The main outcome measure was the Holden Communication Scale (HCS) which measures communication ability. The HCS includes 12 items assessing conversation, awareness, humour, and responsiveness. The score range was from 0 to 48, and a higher score denotes more difficulties with communication [25]. The HCS has been evaluated to be a reliable and valid instrument to measure communication ability in persons with dementia [26].

The degree of cognitive functioning was assessed by the MMSE. The questionnaire comprises 20 questions that cover orientation, memory, reading, calculation, recall, and language. Each question is scored, and the sum score can vary between 0 and 30 . A higher score denotes better cognition [27]. The MMSE has been found to have a satisfactory reliability and construct validity [28]. Residents' characteristics were obtained from their records at baseline (Table 1).

Participants were assessed at baseline (T0), after 12 weeks (T1), and after 24 weeks (T2) by nurses who had received training in the use of the instruments and were not involved in either the Sonas sessions or reading groups. They were blinded at baseline data collection, but this was not possible at follow-ups. 


\section{Data Analysis}

Power Calculation

We aimed at comparing the HCS score between the Sonas and the reading group as the primary analysis, and assumed Cohen's $d=0.80$ as our effect size. With the significance level of $5 \%$ and power of $80 \%$, we estimated a minimum sample size of 24 in each group. A drop-out rate of $30 \%$ was assumed. The sample size required was therefore adjusted to 32 persons per group.

\section{Analysis}

Each participant's characteristics at baseline were summarized as frequencies and percentages for the categorical variables and as means and standard deviations for the continuous variables. The normality of continuous variables was assessed by inspecting histograms.

None of the participants changed the group they originally had been assigned to; hence, there was no need for an intention-to-treat approach.

Differences in HCS total scores between the intervention group, the reading group, and the control group were assessed by estimating a linear mixed model with fixed effects for the time component up to second-order and group variable. Interaction between the two was included as well. A significant interaction term would imply differences between the groups in development of the HCS score through the follow-up period. Random effects for participants nested within nursing homes were included in the model. Such a model correctly accounts for intra-participant correlations due to repeated measurements for each participant as well as cluster effect within each nursing home. The linear mixed model handles unbalanced data by including all available information, also from drop-outs. An exploratory analysis was performed by estimating the same model for each component of the HCS.

A similar model as above was estimated in order to assess changes among those with moderate and with severe cognitive decline. For this purpose, an extra fixed effect for cognitive decline level was included together with the interaction between the level and time and the level and the group with moderate and severe cognitive decline. Such an analysis was performed in order to explore which of these 2 groups benefits most from the Sonas programme compared with the reading and control group.

The statistical analyses were conducted using SPSS version 22 and SAS version 9.4. Results with $p$ values below 0.05 were considered statistically significant.

\section{Ethical Considerations}

The study was approved by the Regional Ethics Committee of Norway (REK) under the registration number IRB 0000 1870. No ethical approval was needed in Ireland, except from the board of management in each nursing home.

\section{Results}

\section{Participant Characteristics}

The mean age of the participants was $84.8 \pm 7.0$ years (range 67-100) and the majority were women $(77.5 \%)$. The mean MMSE score was $9.0 \pm 7.1$. A moderate degree of communication difficulties was seen, with a mean HCS score of $22.0 \pm 11.9$ (Table 1).

\section{Drop-Outs and Attendance}

Of the 120 assessed at baseline, a total of 105 residents completed the study. In the Sonas group, 3 dropped out (2.5\%; 2 left the group and 1 withdrew because of serious illness), 


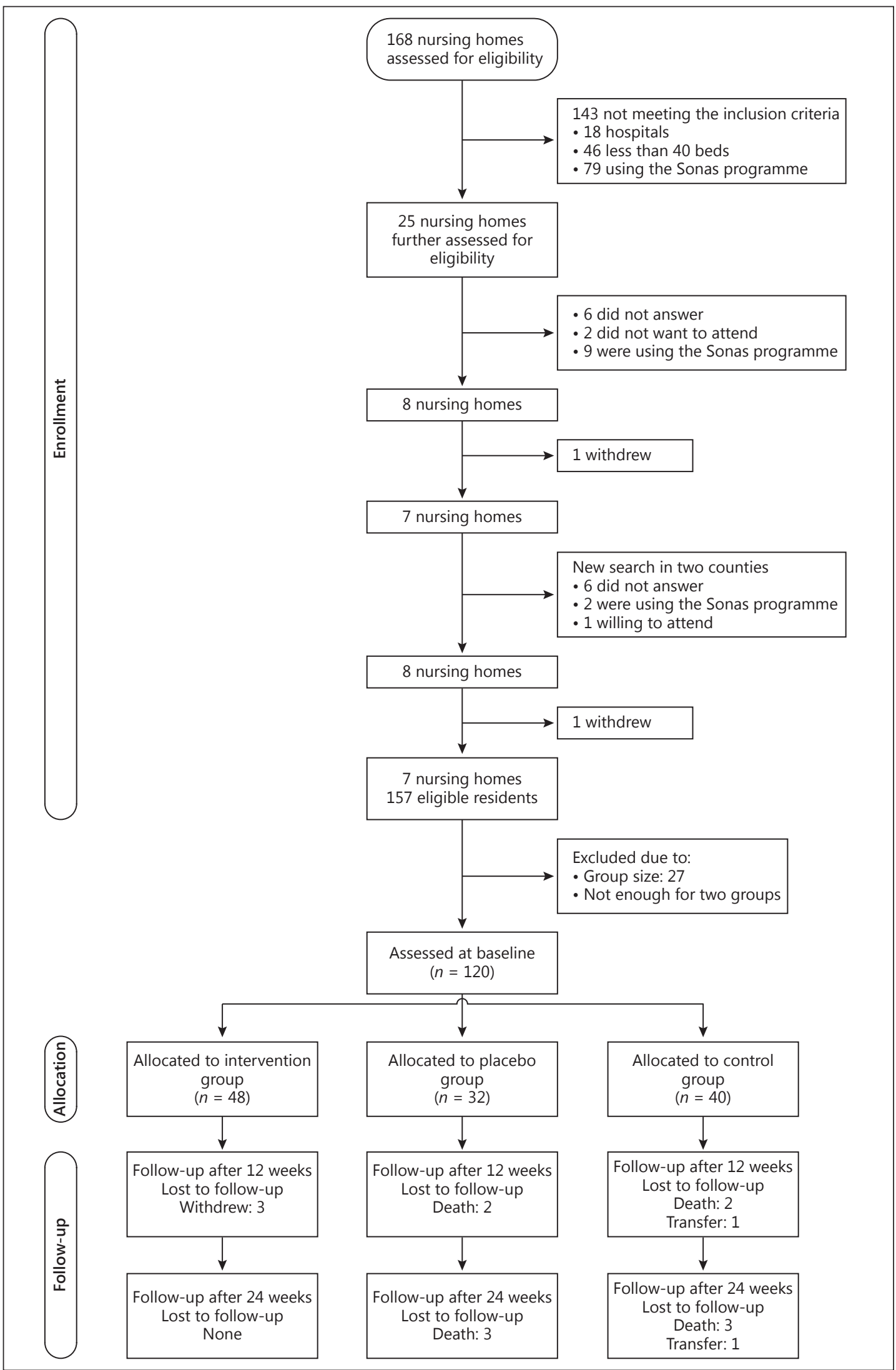

Fig. 2. CONSORT flow diagram. 
Fig. 3. Mean HCS score at baseline, 3 months and 6 months.

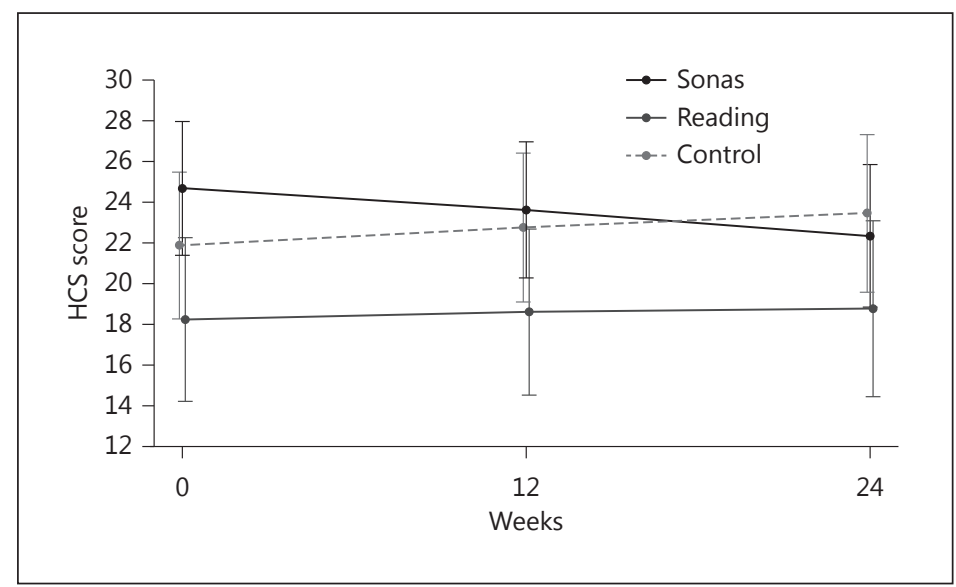

there were 5 drop-outs in the reading group (4.1\%; 5 died) and 7 in the control group (5.8\%; 5 died and 2 were transferred to another nursing home), i.e., a total drop-out rate of $12.4 \%$ (Fig. 2).

The participants were reported to attend the Sonas programme at an average of $39.8 \pm$ 11.8 sessions (range 1-48). In the reading group, the average attendance rate was $42.1 \pm 6.9$ (range 1-48).

\section{Effect of Intervention}

The linear mixed model analysis through 3 time periods (T0, T1, and T2) did not show an overall communication effect of the Sonas programme. However, we found a significant difference in the level of change in communication ability through the whole study period between the Sonas and the reading group $(p=0.019)$ and between the Sonas and the control group ( $p=0.001)$. As illustrated in Figure 3 , the mean HCS score in the Sonas group decreased from 24.7 at T0 to 23.6 at T1 ( $p=0.014)$ and 24.7 at T0 to 22.3 at T2 $(p=0.002)$, indicating a significant improvement in communication abilities. In contrast, the control group had an increase in HCS mean score from 21.9 at T0 to 23.5 at T2. An almost unchanged mean score of HCS was reported for the reading group (18.2 at T0 to 18.8 at T2). The number of sessions attended did not affect the outcome of the HCS.

An overall effect was demonstrated regarding interest in past events, humour and having general knowledge, whereas no significant differences were found in aspects which would be expected to require a higher level of cognitive function such as: remembering names, speech, having success in communication and showing interest in and response to objects. For further details, see Table 2 .

When stratifying on MMSE (moderate and severe; cut-off of 10 points), a significant difference was found between the Sonas group and the reading group among those with an MMSE score of $0-10$ at T0 $(p=0.011)$ and at T1 $(p=0.044)$, while among those with an MMSE score of 11-20, there was a significant difference between the Sonas and the reading group at baseline $(p=0.026)$. No difference was found between the Sonas and the control group. There was a significant reduction in mean HCS score from T0 to T1 ( $p=0.015$ in the group with an MMSE score of 11-20 and $p=0.017$ in the group with an MMSE score of 0-10) and from T0 to T2 ( $p=0.009$ in the group with an MMSE score of 11-20 and $p=0.008$ in the group with an MMSE score of $0-10$ ) in the Sonas group. No significant changes were found in the other 2 groups (Table 3 ). 
Table 2. HCS subtype means and standard deviations

\begin{tabular}{|c|c|c|c|c|c|}
\hline & $\begin{array}{l}\text { Sonas group } \\
(n=48)\end{array}$ & $\begin{array}{l}\text { Reading group } \\
(n=32)\end{array}$ & $\begin{array}{l}\text { Control group } \\
(n=40)\end{array}$ & $\begin{array}{l}\text { Sonas vs. } \\
\text { reading, } \\
p \text { value }\end{array}$ & $\begin{array}{l}\text { Sonas vs. } \\
\text { control, } \\
p \text { value }\end{array}$ \\
\hline \multicolumn{6}{|l|}{ Response } \\
\hline Baseline & $1.8(1.4)$ & $1.5(1.3)$ & $1.7(1.4)$ & \multirow[t]{3}{*}{0.678} & \multirow[t]{3}{*}{0.032} \\
\hline 12 weeks & $1.7(1.3)$ & $1.4(1.2)$ & $1.8(1.4)$ & & \\
\hline 24 weeks & $1.7(1.3)$ & $1.4(1.3)$ & $1.8(1.5)$ & & \\
\hline \multicolumn{6}{|c|}{ Interest in past events } \\
\hline Baseline & $2.4(1.1)$ & $1.8(1.2)$ & $2.1(1.1)$ & \multirow[t]{3}{*}{0.026} & \multirow[t]{3}{*}{0.010} \\
\hline 12 weeks & $2.3(1.2)$ & $1.8(1.1)$ & $2.0(1.1)$ & & \\
\hline 24 weeks & $2.2(1.2)$ & $1.9(1.2)$ & $3.0(1.1)$ & & \\
\hline \multicolumn{6}{|l|}{ Pleasure } \\
\hline Baseline & $1.5(0.9)$ & $1.2(1.0)$ & $1.5(1.0)$ & \multirow[t]{3}{*}{0.035} & \multirow[t]{3}{*}{0.232} \\
\hline 12 weeks & $1.5(1.0)$ & $1.2(1.1)$ & $1.5(0.9)$ & & \\
\hline 24 weeks & $1.3(0.8)$ & $1.2(0.9)$ & $1.2(0.9)$ & & \\
\hline \multicolumn{6}{|l|}{ Humour } \\
\hline Baseline & $2.0(1.2)$ & $1.4(1.1)$ & $1.8(1.3)$ & \multirow[t]{3}{*}{0.018} & \multirow[t]{3}{*}{0.013} \\
\hline 12 weeks & $2.0(1.2)$ & $1.3(1.1)$ & $1.8(1.2)$ & & \\
\hline 24 weeks & $1.9(1.2)$ & $1.6(1.2)$ & $1.8(1.2)$ & & \\
\hline \multicolumn{6}{|c|}{ Remembering names } \\
\hline Baseline & $2.4(1.3)$ & $1.8(1.1)$ & $1.9(1.2)$ & \multirow[t]{3}{*}{0.486} & \multirow[t]{3}{*}{0.413} \\
\hline 12 weeks & $2.4(1.1)$ & $2.0(1.4)$ & $1.9(1.0)$ & & \\
\hline 24 weeks & $2.3(1.1)$ & $1.8(1.2)$ & $1.9(1.0)$ & & \\
\hline \multicolumn{6}{|c|}{ General orientation } \\
\hline Baseline & $3.0(1.2)$ & $2.3(1.3)$ & $2.9(1.1)$ & \multirow[t]{3}{*}{0.047} & \multirow[t]{3}{*}{0.131} \\
\hline 12 weeks & $2.1(1.0)$ & $2.6(1.7)$ & $3.0(1.0)$ & & \\
\hline 24 weeks & $3.1(1.0)$ & $2.7(1.2)$ & $3.0(1.0)$ & & \\
\hline \multicolumn{6}{|c|}{ General knowledge } \\
\hline Baseline & $2.8(1.0)$ & $2.2(1.0)$ & $2.6(1.1)$ & \multirow[t]{3}{*}{0.019} & \multirow[t]{3}{*}{0.022} \\
\hline 12 weeks & $2.8(0.9)$ & $2.2(1.0)$ & $2.6(1.1)$ & & \\
\hline 24 weeks & $2.6(1.0)$ & $2.3(1.1)$ & $2.6(1.0)$ & & \\
\hline \multicolumn{6}{|c|}{ Ability to join in games } \\
\hline Baseline & $2.1(1.3)$ & $2.0(1.6)$ & $2.2(1.3)$ & 0.893 & 0.015 \\
\hline 12 weeks & $2.0(1.2)$ & $1.8(1.2)$ & $1.5(1.4)$ & & \\
\hline 24 weeks & $2.0(1.3)$ & $1.6(1.2)$ & $2.3(1.3)$ & & \\
\hline Speech & & & & & \\
\hline Baseline & $1.7(1.5)$ & $1.1(1.6)$ & $1.1(1.4)$ & 0.319 & 0.063 \\
\hline 12 weeks & $1.6(1.4)$ & $0.9(1.4)$ & $1.2(1.5)$ & & \\
\hline 24 weeks & $1.6(1.3)$ & $0.9(1.4)$ & $1.0(1.4)$ & & \\
\hline Attempts at c & & & & & \\
\hline Baseline & $1.5(1.5)$ & $0.8(1.3)$ & $1.2(1.4)$ & 0.024 & 0.086 \\
\hline 12 weeks & $1.4(1.5)$ & $0.8(1.3)$ & $1.0(1.3)$ & & \\
\hline 24 weeks & $1.4(1.4)$ & $0.9(1.4)$ & $1.0(1.4)$ & & \\
\hline Interest and $\mathrm{r}$ & & & & & \\
\hline Baseline & $1.7(1.3)$ & $1.1(1.2)$ & $1.7(1.1)$ & 0.075 & 0.079 \\
\hline 12 weeks & $1.5(1.2)$ & $1.1(1.1)$ & $1.7(1.2)$ & & \\
\hline 24 weeks & $1.7(1.4)$ & $1.1(1.2)$ & $1.4(1.1)$ & & \\
\hline Success in cor & & & & & \\
\hline Baseline & $1.7(1.4)$ & $1.0(1.1)$ & $1.1(1.4)$ & 0.641 & 0.252 \\
\hline 12 weeks & $1.8(1.5)$ & $0.8(1.3)$ & $0.9(1.3)$ & & \\
\hline 24 weeks & $1.6(1.5)$ & $0.8(1.3)$ & $0.8(1.2)$ & & \\
\hline
\end{tabular}

Figures are means with standard deviations in parentheses. Figures in bold indicate a significant effect. 
Table 3. Ratings of the ability to communicate across time by groups stratified on the level of cognition (MMSE)

\begin{tabular}{|c|c|c|c|c|c|}
\hline Time & Sonas group & Reading group & Control group & $\begin{array}{l}\text { Sonas vs. } \\
\text { reading, } \\
p \text { value }\end{array}$ & $\begin{array}{l}\text { Sonas vs. } \\
\text { control, } \\
p \text { value }\end{array}$ \\
\hline \multicolumn{6}{|l|}{ MMSE score $11-20$} \\
\hline Baseline & $23.9(20.6 ; 27.3)$ & $18.0(14.0 ; 22.0)$ & $20.4(16.8 ; 24.1)$ & 0.026 & 0.380 \\
\hline 12 weeks & $22.7(19.3 ; 26.1)$ & $18.1(14.0 ; 22.2)$ & $20.9(17.1 ; 24.6)$ & 0.092 & 0.325 \\
\hline 24 weeks & $21.5(17.9 ; 25.1)$ & $18.3(13.9 ; 22.8)$ & $21.4(17.4 ; 25.4)$ & 0.267 & 0.301 \\
\hline \multicolumn{6}{|l|}{ MMSE score 0-10 } \\
\hline Baseline & $25.2(22.0 ; 28.5)$ & $18.6(14.5 ; 22.6)$ & $23.3(19.7 ; 27.0)$ & 0.011 & 0.081 \\
\hline 12 weeks & $24.1(20.8 ; 27.4)$ & $18.8(14.8 ; 22.8)$ & $23.9(20.3 ; 27.5)$ & 0.044 & 0.061 \\
\hline 24 weeks & $23.0(19.5 ; 26.5)$ & $19.1(14.8 ; 23.3)$ & $24.6(20.7 ; 28.4)$ & 0.156 & 0.057 \\
\hline \multicolumn{6}{|l|}{ MMSE score 11-20 } \\
\hline 0 vs. 12 weeks & 0.015 & 0.867 & 0.411 & & \\
\hline 0 vs. 24 weeks & 0.009 & 0.792 & 0.319 & & \\
\hline 12 vs. 24 weeks & 0.015 & 0.867 & 0.411 & & \\
\hline \multicolumn{6}{|l|}{ MMSE score 0-10 } \\
\hline 0 vs. 12 weeks & 0.017 & 0.698 & 0.283 & & \\
\hline 0 vs. 24 weeks & 0.008 & 0.608 & 0.194 & & \\
\hline 12 vs. 24 weeks & 0.017 & 0.698 & 0.283 & & \\
\hline
\end{tabular}

Figures are means with 95\% CI in parentheses. Figures in bold indicate a significant effect.

\section{Discussion}

No overall significant effect of the Sonas programme was found. However, there was an intervention effect between the Sonas group and the reading group and between the Sonas group and the control group from T0 to T1 and T2, as well as a significant improvement in communication in the Sonas group. The reading group demonstrated almost unchanged communication ability, while the control group showed a decrease in communication ability. When exploring the subscores of the HCS, a significant improvement in communication ability was found in some of the subscores. Further, a significant effect between the Sonas and the reading group was found for participants with severe dementia after 3 months, but this effect ceased after 6 months. These findings will be discussed in the following.

\section{Effect of the Sonas Programme on Communication}

The lack of an overall significant effect on communication ability in our study is consistent with a previous study [15] and could have different explanations. First of all, there is the challenge of measuring effect in people who are expected to have an increase in cognitive decline as part of the dementia progress, which also affects their communication ability [3]. Another aspect is the importance of tailoring the intervention to the resident's background and preferences [29], choosing music according to the person's cultural context [30] as well as likes and dislikes [31]. Even though our study was carried out in the culture it was developed for, using Irish poetry and music, it was not based on individual preferences, which might also explain the lack of effect. However, the interaction effect found indicates that attending the Sonas sessions could improve communication ability more than by attending the reading group or being part of the control group. It is possible that this could be explained by the multi-sensory approach of the Sonas programme, or by the fact that receiving attention by being part of a reading group is not sufficient to improve 
communication ability. The significant improvement in communication ability in the Sonas group and an almost unchanged mean score on the HCS in the reading group during the 24 weeks could support these findings.

\section{The Impact on Aspects of Communication}

The overall effect on interest in past events, humour and having general knowledge, and lack of effect in remembering names, speech, interest in and response to objects and success in communication could be explained by the fact that sensory stimulation does not have an effect on aspects of communication which require the ability to give a verbal response. Based on this, including persons with severe dementia, who are rarely able to express themselves verbally, demonstrate a challenge and could affect the results. However, we did not expect the Sonas programme to have an effect on general knowledge since the ability to communicate verbally decreased as part of the dementia process [3]. It was also interesting to see a significant effect on humour, which has been described to be altered in persons with dementia [32] and that the ability to understand humour depends on cognitive function [33]. However, the outcome would depend on the staff's interpretation of humour, where they might see smiling as an expression of humour although this has been described as pleasure [25]. It is therefore interesting to observe the significant improvement in pleasure in the Sonas group after 24 weeks, while the reading group remained stable and the control group decreased. An explanation for this could be that pleasure, which is a positive feeling or sensation [34], could be an expression of well-being, which has been reported to be preserved in people with severe dementia [35]. Optimizing well-being is, as described by Threadgold [24], one of the purposes performing the Sonas programme.

\section{Effect on Communication When Stratified on Cognitive Function}

The significant difference in communication ability between the Sonas group compared with the reading group after 12 weeks, when stratified on cognitive function, could have several explanations. First of all implementing something new to a group of people who have difficulties attending other activities offered in the nursing home could explain the effect. At the same time, there is the probability of a greater improvement in this group than for those with moderate dementia since they might be more involved in other activities.

Additionally, lack of communication improvement might be explained by the ceiling effect due to lack of reserve capacity and the fact that dementia is progressing.

Although no previous study of the Sonas programme has measured the effect by stratifying on cognitive function, the findings from our study are consistent with a previous study [36] where they measured the effect of robot-assisted activity on quality of life, reporting a significant effect among people with severe dementia.

The ceased significant effect for the Sonas group with severe cognitive decline, seen after 24 weeks, could be due to progression in dementia or due to the fact that the participants have become bored by attending the same programme twice a week. However, it is important to note that this group was the only group which showed a significant increase in communication ability during the whole study period whereas the other 2 groups showed a decrease.

As well as giving an indication of what aspects of communication are retained in persons with severe dementia, these findings demonstrate that the Sonas programme has a potential to improve communication ability in persons with dementia, emphasizing the importance of individually tailored interventions where the persons cognitive level is taken into account.

\section{Strengths and Limitations}

To our knowledge, this is the first RCT of the Sonas programme carried out in Ireland. To overcome some challenges in previous research, we included a reading group in order to rule 
out a possible effect of social contact by attending the Sonas group. Further, we included a larger sample based on a power calculation. The study was also conducted over a longer period of time compared to a previous study with the same main outcome [15], with a low drop-out rate and high attendance rate over 24 weeks. Another strength was that we focused on communication outcome, which is the overall aim of the Sonas programme. Even though we used a psychometrically tested instrument to assess communication, the HCS is assessing communication deficit and such a negative approach is not in line with the philosophy of the Sonas programme, where the importance is to focus on communication abilities. Further, the subscores in the HCS focus mainly on verbal communication and aspects of communication which require verbal response from the participants that might give a lower outcome on the total score for persons with severe dementia. In order to overcome some of these challenges, we explored the subscores as well as stratified the total score on cognitive function.

Even though all nursing homes were registered with HIQA and therefore had a certain standard, there will always be differences. A limitation is that we did not have control over the participant's daily routine, other activities or stimuli or the use of psychotropic medication, which can affect the outcome. All 6 centres offered some activities, ranging from a singing group once a week to daily activity programme. We assume that the qualification of staff differed among the nursing homes as well as the involvement from the managers. Although all Sonas licensed practitioners had undergone a 3-day formal training, there is no guarantee that the Sonas sessions were conducted in the same way. They can, for example, have different involvement and suitability, or even the way they were prepared for the sessions. Further, the room where the sessions were carried out, the time of the day and if they were interrupted during the sessions would all influence the result.

Although the assessors where blinded at baseline, this was not possible at the 12 and 24 weeks' assessment. However, in order to minimize the risk of contamination, this article's first author collected data after each assessment in order to prevent the assessors from seeing what they scored the previous time. Another limitation was that we were not able to get the same number of groups in all 6 nursing homes, which made the randomization process more difficult. Another consequence of using 6 different nursing homes is the use of 12 different assessors. However, in order to overcome some of the challenges, they underwent a 2-h training about how to carry out the assessment beforehand.

An attention placebo control group with just human presence and no other stimuli might have given other results. However, we found offering human presence without any form of additional stimuli to be unethical and therefore a reading group was chosen as an attention placebo control group.

As the intervention was implemented for people with moderate to severe dementia, the result indicates that this group could benefit from the programme. However, it is not possible to generalize the findings.

\section{Conclusion}

To our knowledge, this is the largest clinical trial examining the effect of the Sonas programme, and the first performed in Ireland. Even though this study failed to document an overall effect of the Sonas programme on communication, the findings indicate that the Sonas programme has a significant effect on those with severe dementia, as well as some aspects of communication.

Further studies are needed to look at the immediate effect during and after sessions, which could be done by the use of Dementia Care Mapping, where the different aspects of communication could be further explored. 


\section{Acknowledgement}

We extend our sincere thanks to the participants and the Sonas licensed practitioners in each nursing home. We would also like to thank Sister Morag Collins SJC for her detailed proof reading.

\section{Disclosure Statement}

The authors declare that they have no conflicts of interest.

\section{References}

1 Prince M, Wimo A, Guerchet M, Ali G-C, Wu Y-T, Prina M: World Alzheimer Report 2015. London, Alzheimer's Disease International, 2015

-2 Stanyon MR, Griffiths A, Thomas SA, Gordon AL: The facilitators of communication with people with dementia in a care setting: an interview study with healthcare workers. Age Ageing 2016;45:164-170.

3 Engedal K, Haugen PK, Brækhus A: Demens: fakta og utfordringer: en lærebok. Tønsberg, Aldring og helse, 2009.

4 Lykkeslet E, Gjengedal E, Skrondal T, Storjord M-B: Sensory stimulation - a way of creating mutual relations in dementia care. Int J Qual Stud Health Well-being 2014;9:23888.

-5 Astell AJ, Ellis MP: The social function of imitation in severe dementia. Infant Child Dev 2006;15:311-319.

6 Kitwood T: Dementia Reconsidered: The Person Comes First. Buckingham, Open University Press, 1997.

7 Spicker A: Dementia and social death. Self Agency Soc 2000;2:88-104.

8 Fossey J, Ballard C, Juszczak E, James I, Alder N, Jacoby R, et al: Effect of enhanced psychosocial care on antipsychotic use in nursing home residents with severe dementia: cluster randomised trial. BMJ 2006;332:756761.

9 Kolanowski A, Fick D, Frazer C, Penrod J: It's about time: use of nonpharmacological interventions in the nursing home. J Nurs Scholarsh 2010;42:214-222.

10 Edvardsson D, Winblad B, Sandman PO: Person-centred care of people with severe Alzheimer's disease: current status and ways forward. Lancet Neurol 2008;7:362-367.

11 Lubinski R: Dementia and Communication. San Diego, Singular Publishing Group, 1995.

12 Vozzella S: Sensory stimulation in dementia care: why it is important and how to implement it. Top Geriatr Rehab 2007;23:102-113.

13 Bakshi R: Assessing the Effectiveness of Sensory Stimulation on Individuals Who Have Moderate to Severe Dementia. New York, New York University, 2004.

-14 Strøm BS, Ytrehus S, Grov E-K: Sensory stimulation for persons with dementia: a review of the literature. J Clin Nurs 2016;25:1805-1834.

-15 Hutson C, Orrell M, Spector A, Dugmore 0: Sonas: a pilot study investigating the effectiveness of an intervention for people with moderate to severe dementia. Am J Alzheimers Dis Other Demen 2014;29:696-703.

16 Brown L: Activating potential for communication. Speech Lang Ther Pract 1997:4-8.

17 Parrish J, Wilshaw J, Baker J: Research: "that was lovely, dear!" evaluating the effects of Sonas. J Dement Care 2005;13:36-37.

18 Jackson GA, Sterling R, Russell K, Templeton G: A multisensory programme: evaluating effects on agitation. Nurs Resident Care 2003;5:126-129.

-19 Iden KR, Engedal K, Hjorleifsson S, Ruths S: Prevalence of depression among recently admitted long-term care patients in Norwegian nursing homes: associations with diagnostic workup and use of antidepressants. Dement Geriatr Cogn Disord 2014;37:154-162.

-20 Egan M, Berube D, Racine G, Leonard C, Rochon E: Methods to enhance verbal communication between individuals with Alzheimer's disease and their formal and informal caregivers: a systematic review. Int J Alzheimers Dis 2010;2010:pii906818.

-21 Schulz KF, Altman DG, Moher D: CONSORT 2010 statement: updated guidelines for reporting parallel group randomized trials. Ann Intern Med 2010;152:726-732.

-22 Boutron I, Moher D, Altman DG, Schulz KF, Ravaud P: Extending the CONSORT statement to randomized trials of nonpharmacologic treatment: explanation and elaboration. Ann Intern Med 2008;148:295-309.

23 Health Information and Quality Authority: National Standards for Residential Care Settings for Older People in Ireland. Dublin, Health Information and Quality Authority, 2016, pp 1-102.

24 Sonas aPc: Sonas Workshop Booklet. 2011.

25 Holden UP, Woods RT: Positive Approaches to Dementia Care. Edinburgh, Churchill Livingstone, 1995. 
Strøm BS, Engedal K, Saltyte Benth J, Grov E-K: Psychometric evaluation of the Holden Communication Scale (HCS) for persons with dementia. BMJ Open 2016;6:e013447.

27 Folstein MF, Folstein SE, McHugh PR: "Mini-mental state." A practical method for grading the cognitive state of patients for the clinician. J Psychiatr Res 1975;12:189-198.

-28 Tombaugh TN, McIntyre NJ: The mini-mental state examination: a comprehensive review. J Am Geriatr Soc 1992;40:922-935.

29 Cohen-Mansfield J, Dakheel-Ali M, Marx MS: Engagement in persons with dementia: the concept and its measurement. Am J Geriatr Psychiatry 2009;17:299-307.

-30 Sung HC, Chang AM, Lee WL: A preferred music listening intervention to reduce anxiety in older adults with dementia in nursing homes. J Clin Nurs 2010;19:1056-1064.

31 Nair BK, Heim C, Krishnan C, D’Este C, Marley J, Attia J: The effect of Baroque music on behavioural disturbances in patients with dementia. Australas J Ageing 2011;30:11-15.

-32 Clark CN, Nicholas JM, Gordon E, Golden HL, Cohen MH, Woodward FJ, et al: Altered sense of humor in dementia. J Alzheimers Dis 2015;49:111-119.

33 Takeda M, Hashimoto R, Kudo T, Okochi M, Tagami S, Morihara T, et al: Laughter and humor as complementary and alternative medicines for dementia patients. BMC Complement Altern Med 2010;10:1-7.

34 Persaud ML: Pleasure in the Daily Lives of People Living with Advanced Dementia in a Long-Term Care Facility: A Multiple Case Study Approach. Toronto, University of Toronto, 2009.

-35 Mayhew PA, Acton GJ, Yauk S, Hopkins BA. Communication from individuals with advanced DAT: can it provide clues to their sense of self-awareness and well-being? Geriatr Nurs 2001;22:106-110.

36 Joranson N, Pedersen I, Rokstad AM, Ihlebaek C: Change in quality of life in older people with dementia participating in Paro-activity: a cluster-randomized controlled trial. J Adv Nurs 2016;72:3020-3033. 